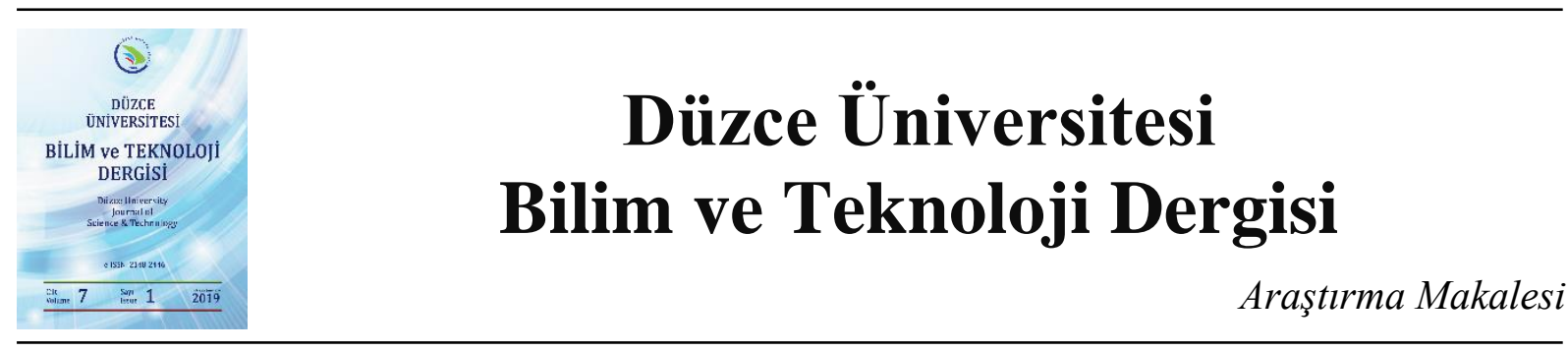

\section{Bitkisel Bir Hidrolik Akışkan Üretimi ve Performansının Hidrolik Yağ ile Karşılaştırılması}

\author{
Gürcan SAMTAŞ ${ }^{\text {a,* }}$, Salih KORUCU ${ }^{b}$ \\ ${ }^{a}$ Mekatronik Mühendisliği Bölümü, Mühendislik Fakültesi, Düzce Üniversitesi, Düzce, TÜRKIYE \\ ${ }^{b}$ Imalat Mühendisliği Bölümü, Teknoloji Fakültesi, Gazi Üniversitesi, Ankara, TÜRKiYE \\ * Sorumlu yazarin e-posta adresi: gurcansamtas@duzce.edu.tr
}

\begin{abstract}
ÖZET
Günümüzdeki modern dünyada hidrolik; gün geçtikçe birçok alanda insanların yaşantısında çok önemli pay sahibi olmaktadır. Hidrolikte enerjiyi sağlayan temel unsur akışkandır ve akışkana yön veren ekipmanlar valfler olarak adlandırılır. Valflerin genel olarak doğrudan el ile ya da elektriksel sinyal vasitasıyla kumanda edilmesi, hareketli hidrolik sistemin karakteristik bir özeliğidir. Bir hidrolik sistemde en önemli tek malzeme kendi kendine çalışan hidrolik akışkandır. Hidrolik yağın karakteristik özellikleri, ekipmanların performans ve ömürleri üzerinde büyük bir etkiye sahiptir. Dolayısıyla yüksek kalitede temiz bir akışkan kullanarak etkili bir hidrolik sistem oluşturulabilir. Ayrıca hidrolik sistemlerde bulunan sıvı akışkan, iş elemanı olarak silindirler içerisinde ne kadarlık bir güç üreteceğini de belirler. Diğer taraftan bir hidrolik akışkan; gücün iletimi, hareket elemanlarının yağlanması, eş parçalar arasında conta görevi ve sistemde 1sı dağılımı gibi amaçlar için de kullanııır. Bu çalışmada, doğada rahatça bulunabilen bitki ve bitki tohumları kullanılarak üretilen hidrolik akışkanın, viskozite indeksi 22 olan normal hidrolik yağ ile karşılaştırılması sunulmuştur. Karşılaştırmalar farklı elektro-hidrolik devrelerle yapilmış ve yüke karşı yürütülen deneylerle hidrolik devre elemanlarının sıcaklıkları incelenmiştir.
\end{abstract}

Anahtar Kelimeler: Hidrolik, Hidrolik Akışkan, Hidrolik Devreler

\section{Comparison of Vegetable Hydraulic Fluid Production and Performance with Hydraulic Oil}

\begin{abstract}
In today's modern world hydraulics have a very important share in the lives of people in many areas day by day. The basic element that provides energy in hydraulics is the flow and the equipment that directs the flow is called the valves. The control of the valves, generally directly or by means of an electrical signal, is a characteristic feature of the moving hydraulic system. The most important single material in a hydraulic system is the selfrunning hydraulic fluid. The characteristics of the hydraulic oil have a great influence on the performance and lifetime of the equipment. Therefore, an efficient hydraulic system can be created by using a clean fluid at high quality. In addition, the liquid fluid in the hydraulic systems also determines how much power is generated in the cylinders as a workpiece. On the other hand, a hydraulic fluid is also used for some purposes such as power transmission, lubrication of moving elements, sealing between co-parts and heat distribution in the system. In this
\end{abstract}


study, a comparison of the hydraulic fluid produced by using plant and plant seeds, which can be found easily in nature with the normal hydraulic oil with viscosity index of 22 was presented. The comparisons were made with different electro-hydraulic circuits and the temperatures of the hydraulic circuit elements were investigated by experiments against load

Keywords: Hydraulic, Hydraulic fluid, Hydraulic circuits

\section{GiRISS}

$\mathrm{B}$ asit anlamda hidrolik, İngilizcede "borular içindeki su" anlamı taşımaktadır [1]. Her yıl litrelerce yağ kullanımdan ötürü doğaya bırakılmakta, bunun sonucunda da yer altı suları kirlenmekte, hayvanlar ve bitkiler zehirlenmektedir. Bunun en iyi örneğini ormanlarda ağaç kesmek için kullanılan hidrolik kesicileri verebiliriz. Dolayısıyla çevre dostu hidrolik yağların bu amaçlar için kullanımı, doğayı kirletmesini önemli derecede azaltmaktadır. Çevre dostu yağ kullanımında araştırmayı bekleyen bazı sorular vardır. Bunların içerisinde en önemli olanları; yeni ürünlerle karıştırılıp karıştırılamayacağı, yüksek sıcaklık limitlerinin ne olacağı, kullanılan yağların çevre tarafından ne zaman emilebileceği ve çevre bakımından uygunluğunun ne olduğudur [2]. Diğer taraftan önceki yıllardan günümüze kadar uzanan çalışmalarda su hidroliğinin endüstriyel uygulamalarda yerini aldığını görmekteyiz. Suyun kullanımlarda en önemli dezavantajı düşük viskozite değeri nedeniyle sistemde su kaçaklarının meydana gelmesidir. Diğeri ise, düşük viskozite değeri nedeniyle büyük yüklerde istenilen performansı verememesidir. Sanayi uygulamaları açısından değerlendirdiğimizde ise yağ hidroliğin uygulanabilirliği sudan daha fazladır [3]. Suyun hidrolikte düşük güç üretimi risklerinin dışında oldukça fazla avantaja sahiptir. Suyun çevre dostu oluşu, toksik madde içermemesi, alev almaması, maliyet açısından ucuz oluşu ve termal iletkenliği mineral yağdan 4-5 kat fazla oluşu onu göz önüne çıkarmaktadır. Ancak burada en önemli faktör güç üretebilmesidir. Saf su hidroliği düşük viskozite değerine sahiptir. Aynı koşullar ve iletim yolları altında, yağdan 30 kat daha fazla sızdırabilirliği mevcuttur. ISO VG 32 tanımlamasına sahip bir hidrolik yağın kinematik viskozite değeri $40{ }^{\circ} \mathrm{C}$ de (normal çalışma şartları) $28,8 \mathrm{cSt}$ iken $40{ }^{\circ} \mathrm{C}$ de suyun viskozite değeri $0,66 \mathrm{cSt}$ 'dur [4]. Suyun düşük viskozitesi nedeniyle su hidroliği yağ hidroliğinden daha gürültülüdür [5].

Bitkilerden elde edilen hidrolik yağlar günümüzde çevre kirliliğine karşı hidrolik sistemlerde kullanılan en iyi yöntemlerden biridir. Özellikle ormanlık alanlarda hidrolik ekipmanlarla yürütülen işlerde, madenlerde ve diğer çevre kirliliğine karşı duyarlı olunması istenilen dış ortamlarda bitkilerden elde edilen yağlar günümüzde yaygın bir şekilde kullanılmaktadır [6]. Sebze türevi (bitkisel) yağlar yüksek viskozite indeksi, yüksek kayganlık diğer yağlar esas alındığında düşük buharlaşma ve yağlama özelliğine sahiptir. Günümüzde bitki esaslı hidrolik sıvı olarak kullanılan bitkisel yağ türleri ve biyolojik hidrolik sıvılar; doymamış esterler (kozla tohum yağı, ayçiçek tohum yağı, mısır, soya fasülyesi, kanola, Hindistan cevizi vb.), doymuş ve doymamış sentetik esterler ve diğer temel sıvılar (petrol esaslı ürünler, polialfaolefinler vb.) şeklinde ifade dilebilir [7]. Xavier vd. yaptığı çalışmada, dört farklı bitkisel ve mineral bazlı hidrolik yağları yüksek basınçlarda sıcaklık ve basınca karşı viskozite indekslerindeki değişimleri incelemişlerdir [8]. Acaroğlu yaptığı çalışmada, ormancılıkta ve tarım makinalarında biyolojik ayrışabilir yağların hidrolik yağı olarak kullanılmasını araştırmıştır. Bu çalışmada önemli nokta; çevre koruyucu yağlayıcılarla ilgili çalışmalarda hedef, bir yandan uygulama alanlarında çevresel tehlike potansiyellerinin belirlenmesi diğer yandan da somut olarak verimliliklerinin araştırılması 
gerektiğinin vurgulanmasıdır [9]. Endüstriyel yağların önemli bir kısmı, hidrolik sistemlerin temel elemanı olarak kullanılmaktadır. Bunların arasında petrol kökenli ve sentetik hidrolik yağlar, kullanılacakları hidrolik ortama göre çeşitli özellikleri taşıması gerekmektedir. Durak vd. yaptıkları çalışmalarda, günümüzde hidrolik sistemlerde kullanılan yağların karakteristik özelliklerini belirleyerek, bu özelliklerin bir ya da birkaçını katkı maddeleri ile hidrolik yağa nasıl kazandırılacağını detaylı bir şekilde ifade etmişlerdir [10]. Hidrolik sistemlerde sıkça rastlanan sorunlardan bir tanesi de yağ içinde hava problemidir. Bunun nedeni sızdırmazlık elemanlarının deformasyonu ya da hidrolik sistemdeki yağın çeşitli nedenlerden dolayı viskozite değerinin düşmesidir. Demiralp, yaptığı çalışmada hidrolik silindir içindeki havanın yağ ile beraber oluşturabileceği olumsuz yönleri incelemiştir [11]. Kazuhisa vd. yaptıkları çalışmada, su hidroliği kullanarak basit bir servo silindir sisteminin performansını incelemişlerdir. Çalışmalarında referans uyarlanabilir kontrol ve basit uyarlanabilir kontrol kullanarak servo valfi test etmişlerdir. Su hidroliğinde tam bir kontrol için temel problem; atık akışları ve büyük sürtünme torkları yüzünden aşırılığa kaçınılması ve durağan durum hatalarıdır. Ayrıca bu çalışmada, bu tip sistemlerde yüksek valf tepkileri nedeniyle, uygulanabilecek kontrol türlerinin iyi bir şekilde seçilmesi gerektiğini vurgulamışlardır [12]. Uluslararası alanda hidrolik sistemler balıkçı teknelerinde (vinçler, kayar vinçler ve sürücü üniteleri), tarımsal operasyonlarda ve deniz mahsülleri işleme ünitelerinde yaygın bir şekilde kullanılmaktadır. Bu kullanımlarda öne çıkan nokta kullanılan yağın çevreyi en az nitelikte kirletmesidir. Christensen vd. yaptıkları çalışmada balık yağını hidrolik yağ olarak kullanılabilirliğini araştırmışlardır. Çalışmalarının amacı; kullanılan balık yağının geleneksel olarak kullanılan hidrolik yağlardan çevresel, fiyat ve devre elemanlarının ömrü yönelik incelenmesidir. Çalışmalarının sonunda, kullandıkları bu balık yağı sistem sıcaklığına ulaştı̆̆ında balık kokusu oluşturduğunu ve bu kokudan dolayı yağın sadece dış ortamlarda kullanılabilirliğine bakmak gerektiği ifade edilmiştir [13]. Son zamanlarda saf suyun hidrolik sistemlerde kullanılabilirliği artmış olup bunun iki önemli nedeni vardır. Bunlardan biri çevreyi kirletmemesi, düşük maliyetli oluşu ve alevlenme özelliğinin olmayışıdır. Majdic vd. yaptıkları çalışmada, hidrolik yağına alternatif olarak saf su (damıtılmış) kullanmışlardır. Çalışmalarında su ile çalışabilen hidrolik devre elemanları kullanılmıştır ve performans olarak paslanmaz çelikten üretilmiş $4 / 3$ yon kontrol valfi test edilmiştir. Test sistemlerinin yapısı suya uygun olarak tasarlanmış ve 160 bar ve dakikada 30 litre kapasitesine sahip hidrolik pompa kullanılmıştır. Bu çalışmada, su esaslı 4/3 yön kontrol valfi 10 milyondan fazla iş turu yaptırılmış ve bunun sonunda valf kesilerek içyapısı SEM görüntüleri ile incelenmiştir [14]. Suyun kullanıldığı bu tarz hidrolik sistemlerde yapı malzemesi olarak bazı seramik malzemelerinin kullanılması bu aşınmaların daha da azaltılmasını sağlayabilir [15-17]. Değişik yapidaki hidrolik akışkanlar, günümüzde servo valf sistemlerinde de denenmektedir. Li ve Bao yaptıkları çalışmada manyetik özellikli hidrolik akışkanı, hidrolik servo tork motorun çalışma boşluğunun için doldurarak performansını test etmişlerdir. Dinamik olarak matematiksel modelini oluşturduktan sonra manyetik akışkanlı tork motor, analiz ve test edilmiştir [18]. Manyetik akışkanlar, manyetik bir alana maruz kaldıklarında yüksek viskozite ve manyetik doyuma ulaşırlar. Eğer bu yă servo motoru çalışma boşluğunu dolduruyorsa bu hidrolik servo valf tork motoru manyetik akışkan tarafindan yüksek sönümleme ve dayanıma ulaşır. Li ve Song yaptığı çalışmada, manyetik akışkanlı bir hidrolik servo tork motorun dinamik yanıtını incelemişlerdir [19]. Gün geçtikçe kullanımı artan biyolojik açıdan parçalanabilen yağlar, eko toksisite özelliği oldukça düşüktür [20]. Bu alanda yürütülen yenilikçi ve güncel araştırmalar günümüzde farklı tipte doğada çözünebilen yağları bizlere sunmaktadır. Kamalakar vd. yaptıkları çalışmada, kauçuk tohumu yağının hidrolik yağ olarak kullanılabilirliğini araştırmışlardır [21]. Yapılan literatür çalışmasından anlaşıldığı gibi doğada çözünebilen yani çevreyi kirletmeyen hidrolik yağ konusunda henüz bir çalışma başlatılmadığı görülmektedir. Laboratuvar ortamında kolay üretilmesi açısından su kullanımı bu alanda yapılacak çalışmalar açısından en pratik olandır. $\mathrm{Bu}$ çalışmada bitki karışımlarının kaynatılmasıyla elde edilen çevreye karşı duyarlı bir hidrolik akışkanın, ISO VG 22 hidrolik yağ ile karşılaştırılması verilmiştir. 


\section{MATERYAL MeTOT}

Bitki karışımlarının kaynatılmasıyla elde edilen hidrolik akışkan için ilk olarak, Human Power I Scholar-UV marka saf su cihazında ters ozmos filtreleme yöntemi kullanılarak saf su elde edilmiştir. Daha sonra 5 lt saf suya dört farklı (Tablo 1) bitki türü belirli oranlarda katılarak karışım kaynatılmıştır. Kaynatma sonucunda elde edilen sıvı viskozitesinin ölçümü için Fungilab Smart marka viskozimetre kullanılmıştır. Ölçümler sık sık tekrarlanarak ideal değer bulunana kadar devam edilmiştir. İdeal viskozite değerine, ISO 4406 standardı dikkate alınarak ISO VG 22 ile ISO VG 100 ya da diğer bir ifadeyle $20 \mathrm{cSt}-100 \mathrm{cSt}\left(20 \mathrm{~mm}^{2} / \mathrm{sn}-100 \mathrm{~mm}^{2} / \mathrm{sn}\right)$ aralığına ulaşılmaya çalışılmıştır. Çalışmada elde edilecek sıvı için kullanılan saf su içerisine kaynama noktasında bitkiler eklenerek viskozite indeksi yükseltilmeye çalışılmıştır. Bitkiler suyun kaynama noktasında sıvıya koyuluk kazandırmaktadır. Kullanılan bitkiler, hatmi çiçeği, karahindiba, meyan kökü ve keten tohumudur. Bu bitkilerin her biri saf su içine Tablo 1'de belirtilen oranlarda karıştırılmıştır. Bitkilerle saf suyun birleştirilmesi için bir adet küçük tüp ve kaynatma tenceresi kullanılmıştır.

Tablo 1. Kullanılan bitki türleri

\begin{tabular}{ccc}
\hline Adı & Kullanım Şekli & $\begin{array}{c}\text { Karışım } \\
\text { Oranı }\end{array}$ \\
\hline Hatmi Çiçeği & Çiçek & $\% 20$ \\
Karahindiba & Gövde, yaprak ve kök & $\% 20$ \\
Meyan Kökü & Kök & $\% 20$ \\
Keten Tohumu & Tohum & $\% 40$ \\
\hline
\end{tabular}

Tablo 1'de bu çalışma kapsamında kullanılan bitkiler ve karışım oranları verilmiştir. En yüksek karışım oranı keten tohumuna aittir. Keten tohumu, sıcak suyla karıştıııldığında jölemsi bir kıvam oluşturmaktadır. Karahindiba, elde edilen sıvının köpüklenmesini azaltmaktadır. Meyan kökü ve hatmi çiçeği, sıvıya ağdalı bir kıvam kazandırmaktadır. Pratikte viskozite sınırları önemli bir rol oynamaktadır. Viskozite değeri çok düşükse (çok sıvı hal) çok fazla sızıntılar ortaya çıkar. Yağlayıcı film incedir ve böylece aşınmaya karşı koruma da azalır. Basınç ve güç kayıpları düşük sürtünme nedeniyle küçük olduğu için zor akışlı yağ tercih edilmektedir. Viskozite arttıkça sıvının iç sürtünmesi artar ve ısının artmasıyla basınç ve güç kaybı olur. Yüksek viskozite özellikle boğaz noktalarında aşırı 1sı ve basınca yol açan sürtünmeyi arttırmaktadır. Bu durum hava kabarcıklarını ayırdığı için kavitasyona yol açar. Tablo 2'de ideal viskozite aralığı gösterilmiştir [22].

Tablo 2. Viskozite limitleri [22]

\begin{tabular}{ll}
\hline Limitler & Kinematik viskozite \\
\hline Alt limit & $10 \mathrm{~mm}^{2} / \mathrm{sn}$ \\
İdeal viskozite aralığ & $15-100 \mathrm{~mm}^{2} / \mathrm{sn}$ \\
Üst limit & $750 \mathrm{~mm}^{2} / \mathrm{sn}$ \\
\hline
\end{tabular}

Hidrolik akışkanlar kullanıldığında, hidrolik akışkanın sıcaklık değişimlerinde viskozitesi değiştiği için viskozite-sıcaklık özelliklerini göz önünde bulundurmak önemlidir. Bu çalışma kapsamında ideal viskozite aralığı $15-100 \mathrm{~mm}^{2} / \mathrm{sn}$ olarak alınmıştır. Çalışma kapsamında dört farklı viskozite değerine sahip sıvı üretilmiştir. Elde edilen sıvılar ilk olarak yoğunlukları tespit edilmiş, daha sonra bu yoğunluk değerleri Fungilab marka viskozimetreye girilerek viskozite değerleri $\left(\mathrm{mm}^{2} / \mathrm{sn}\right.$ ya da cSt) ölçülmüştür. Karşılaştırma deneyleri için en yüksek viskozite değerine sahip sıvı seçilmiştir. Bu sıvının ortalama viskozite değeri $47.6560 \mathrm{~mm}^{2} / \mathrm{sn}$ (cSt) olarak tespit edilmiş ve sıvı 1,5 saat kaynatılmıştır. Daha sonra 
elde edilen sıvı ile ISO VG 22 hidrolik akışkan elektro-hidrolik devre elemanlarıyla karşılaştırılmıştır. Karşılaştırma deneylerinde Şekil 1'de yer alan deney düzeneği kullanılmıştır.
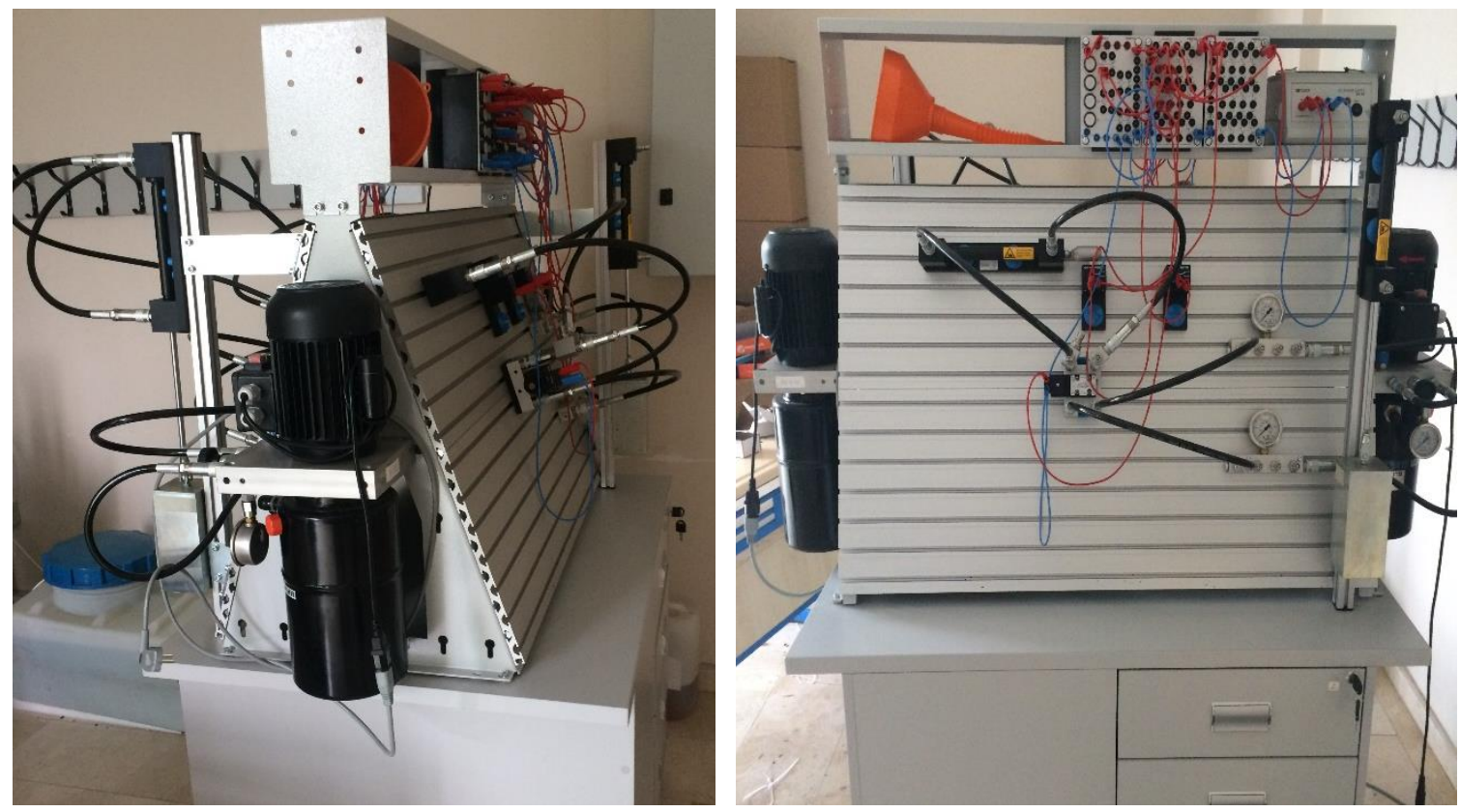

Şekil 1. Karşılaş̧ırma deneyleri için kullanılan deney düzeneği

Deneyler için aynı tipte iki paket güç ünitesi ve devre elemanları temin edilmiştir. Güç üniteleri maksimum 60 bar basınçta çalışmakta olup, deneyler 30 bar basınçta gerçekleştirilmiştir.

\section{PERFORMANS DENEYLERI}

Çalışmada ilk olarak farklı devre şemaları kullanılarak karşılaştırma deneyleri yapılmış, daha sonra silindirlere $9 \mathrm{~kg}$ yük başlanarak yüke karşı deneyler yapılmıştır. Çalışma kapsamında üretilen sıvılardan, $47.6560 \mathrm{~mm}^{2} / \mathrm{sn}$ viskozite değerine sahip sıvı kullanılmak üzere seçilmiştir. Seçilen sıvı ile doldurulan hidrolik sistem 30 bar basınca ayarlanmıştır. 30 bar basınçla yürütülen ilk deneylerde, 10 farklı devre şeması kullanılmıştır. Çalışmanın ikinci kısmında yüke karşı hidrolik sistem zorlanmıştır. Ağırlık olarak 9 kg'lık yük kullanılmıștır. Ancak iki saatlik bir süre sonunda hidrolik sıvının kullanıldığı pompa arıza vermiştir. İki saatlik deney sonunda Fluke Ti250 termal kamera ile hidrolik valfler, silindirler, tank ve elektrik motoru 1sısı ölçülmüştür. Ölçümlerde deney düzeneğinin bulunduğu ortam sıcaklığı $22^{\circ} \mathrm{C}$ 'dir. Yük deneyi ile kurulan devre şeması Şekil 2'de gösterilmiştir. 

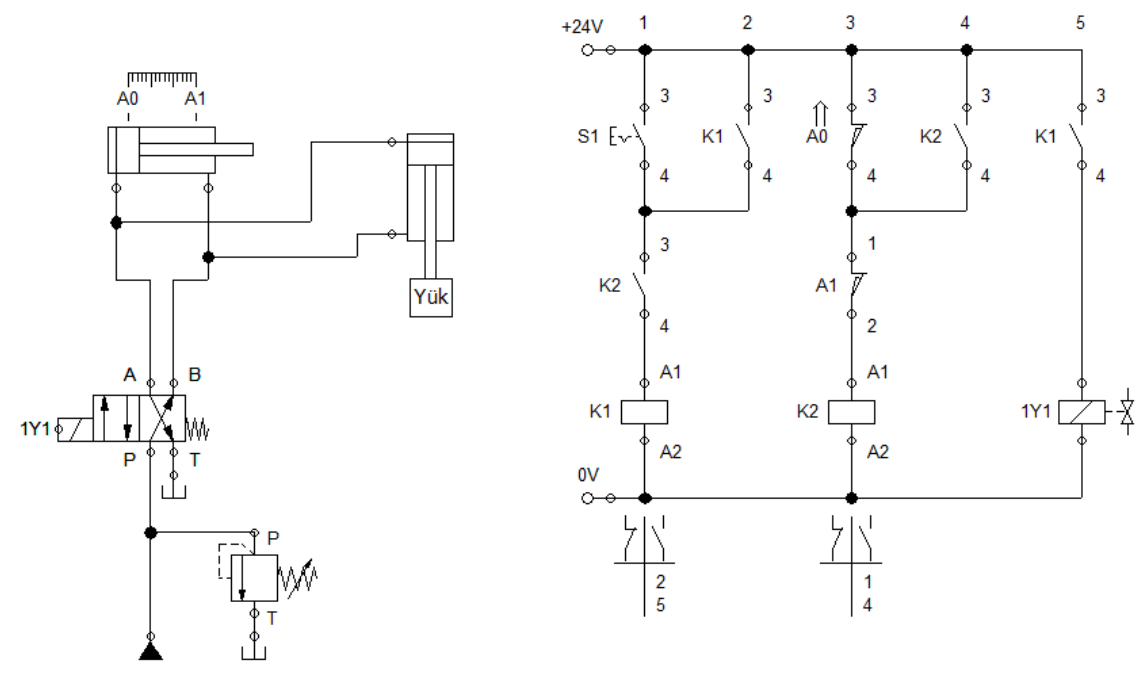

Şekil 2. Yüke karşı yapılan deneyde kullanılan devre şeması [23]

Deneylerde kullanılan ekipmanlar Şekil 3'de gösterilmiştir.

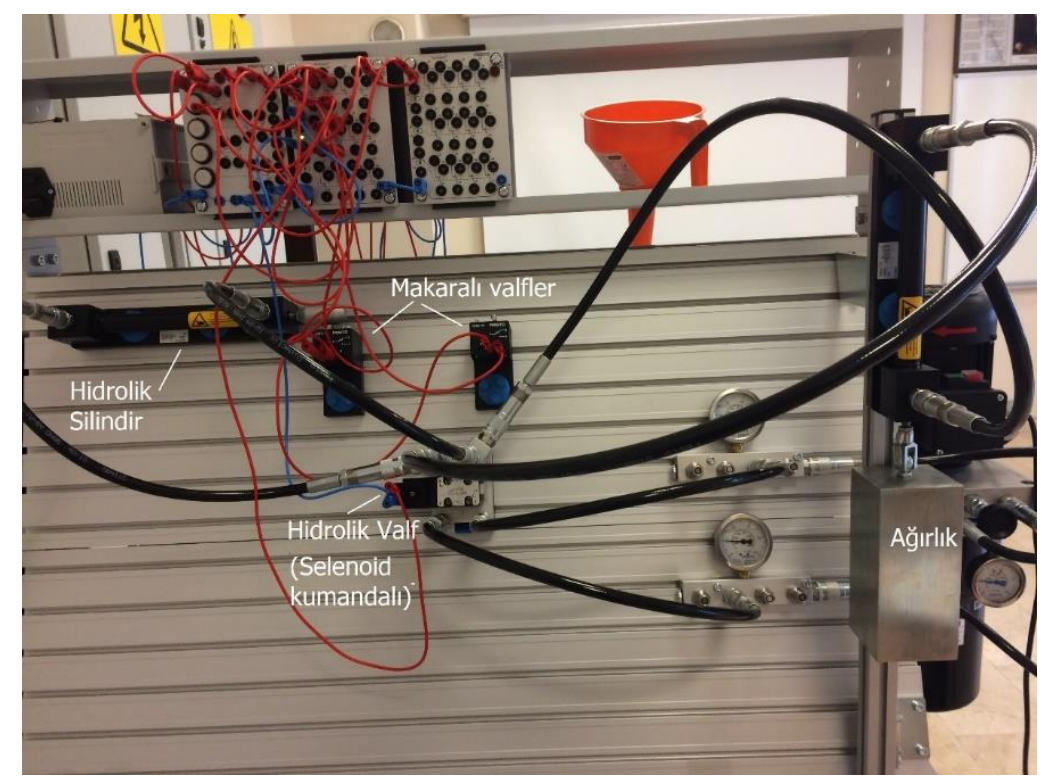

Şekil 3. Yük deneyinde kullanılan devreler ve açıklamaları

Deneylerde elektrohidrolik devre elemanları kullanılmıştır. Kullanılan ekipmanlar Festo firmasından temin edilmiştir. Hidrolik sıvının kullanıldığı ilk deneyde elektrik motorunun termal görüntüsü Şekil 4'de gösterilmiştir. Şekil 4'de görüldüğü gibi elektrik motorundaki sıcaklık $55.5{ }^{\circ} \mathrm{C}$ 'ye kadar çıkmıştır. Ortalama sıcaklık değeri $53{ }^{\circ} \mathrm{C}$ olarak ölçülmüsstür. Ölçümlerde kullanılan termal kameranın salınım gücü 0.95 'tir. Bu değer termal kameranın frekans değerini vermektedir. Aynı deneyde silindirdeki isı dağılımı Şekil 5'de gösterilmiştir. Şekil 5'de görüldüğü gibi silindirdeki sıcaklık $30{ }^{\circ} C^{\prime}$ ye kadar çıkmıştır. Yine aynı deneyde hidrolik tanktaki 1sı dağılımı Şekil 6'da gösterilmiştir. Şekil 6'da görüldüğü gibi hidrolik tanktaki sıcaklık $42.9^{\circ} \mathrm{C}$ 'ye kadar çıkmıştır. Yürütülen aynı deneyde hidrolik valfteki 1S1 dağılımı Şekil 7'de gösterilmiştir. Şekil 7'de görüldüğü gibi hidrolik tanktaki sıcaklık 34.4 ${ }^{\circ} \mathrm{C}$ 'ye kadar çıkmıştır. Burada minimum sıcaklık $30.9{ }^{\circ} \mathrm{C}$, Maksimum sıcaklık $34.4{ }^{\circ} \mathrm{C}$ olarak ölçülmüştür. 

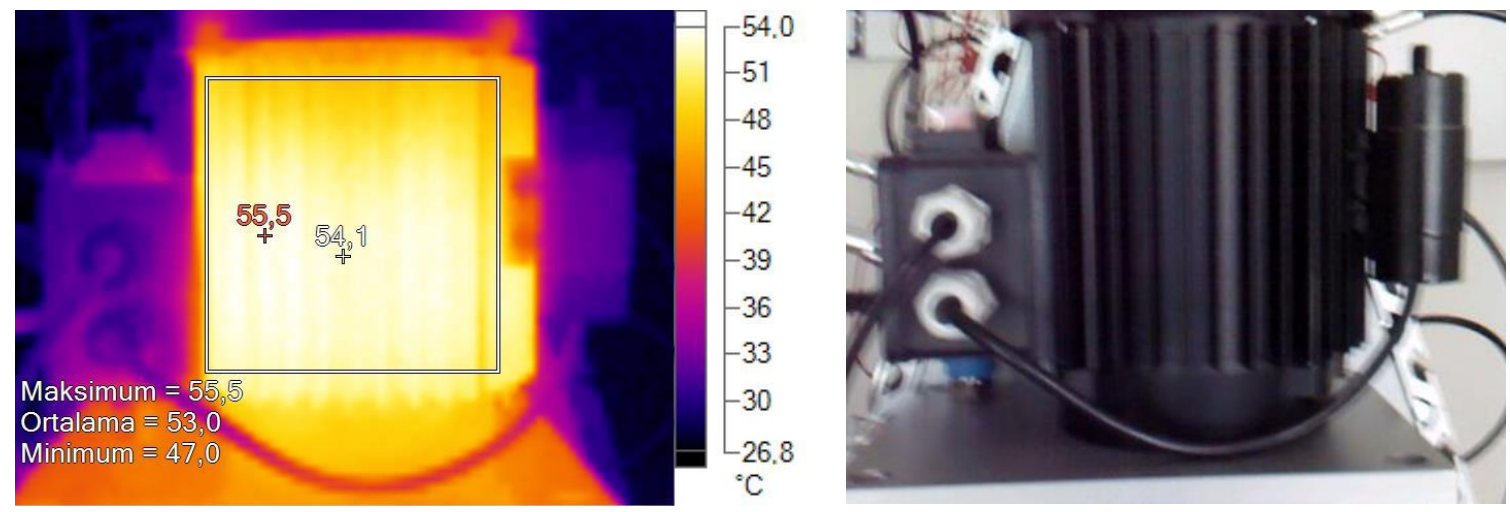

Şekil 4. Sıvı deneyi için elektrik motorunun termal ve normal görüntüsü
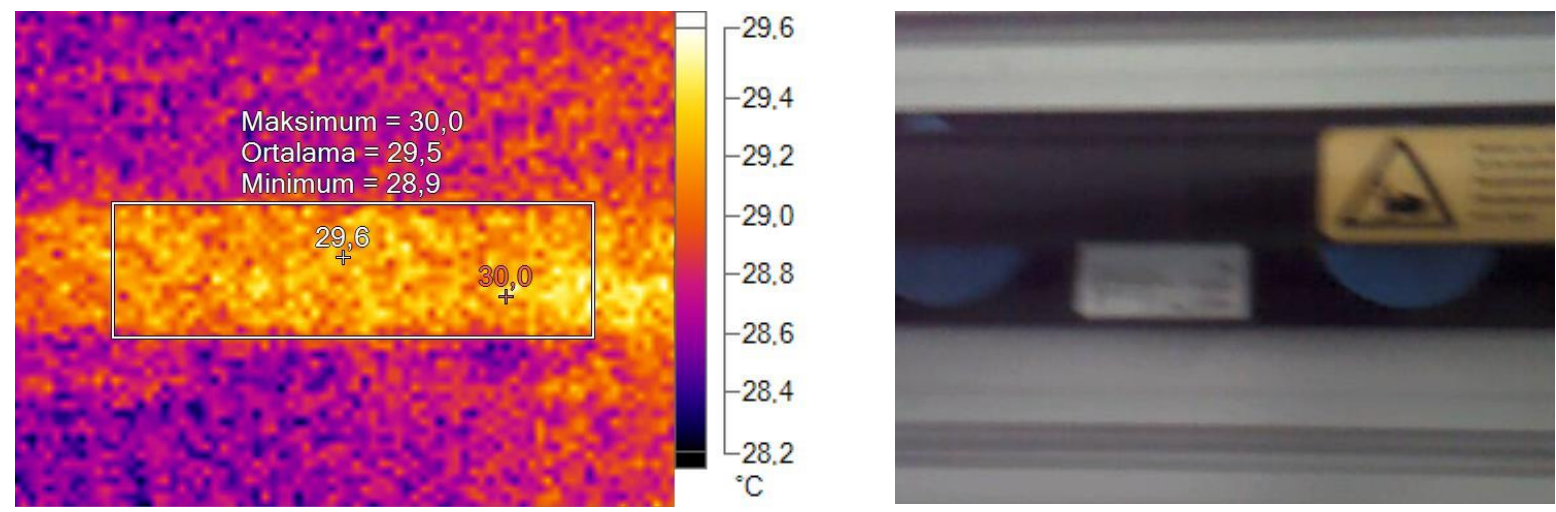

Şekil 5. Sıvı için yürütülen deneyde silindirin termal ve normal görüntüsü
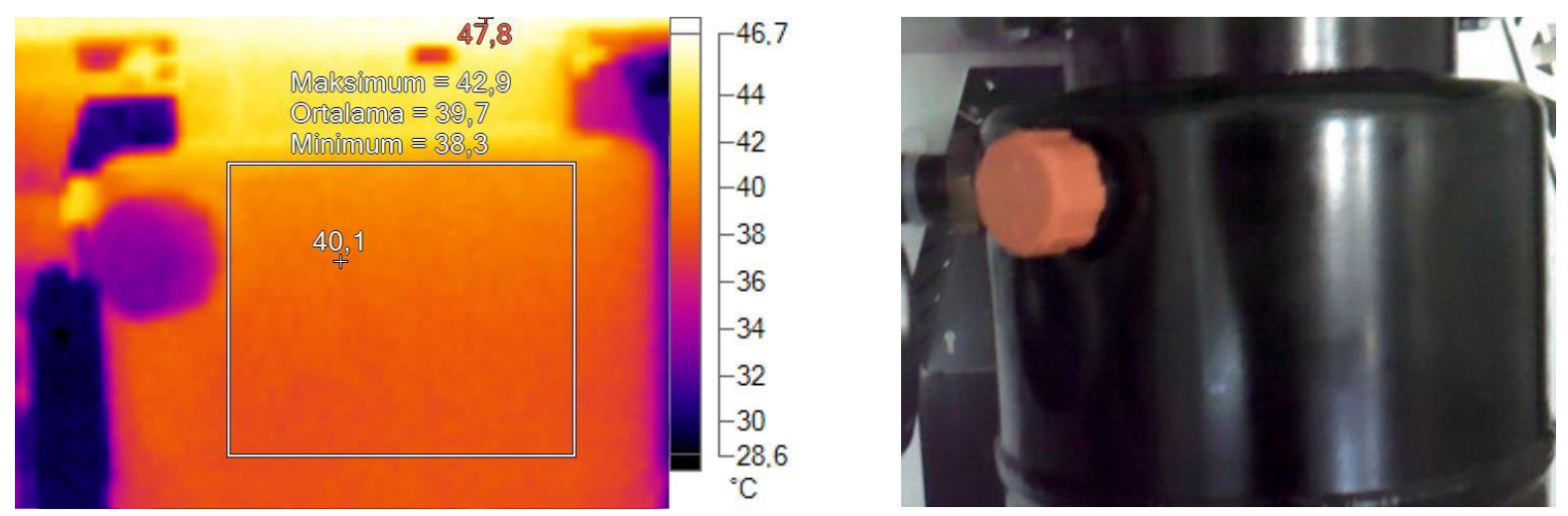

Şekil 6. Sıvı için yürütülen deneyde tankın termal ve normal görüntüsü 

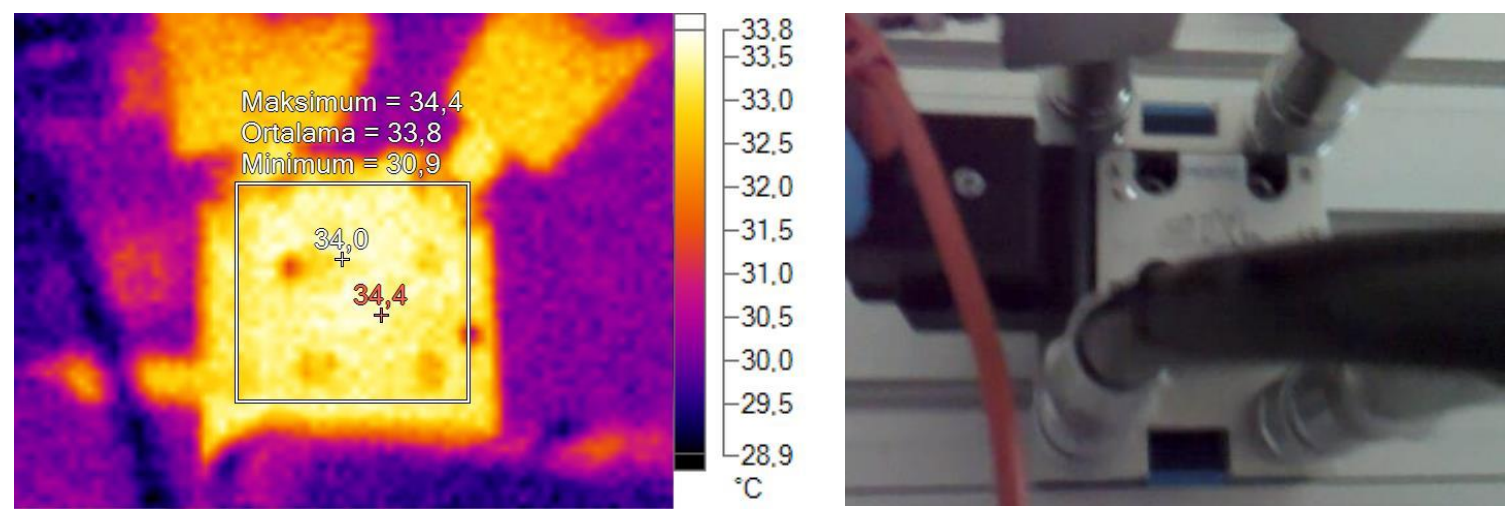

Şekil 7. Sivı için yürütülen deneyde valfin termal ve normal görüntüsü

Hidrolikte akışkan gücünden faydalanıldığı bilinmektedir. Akışkan sıkıştırılamaz bir özelliğe sahip olduğu için hidrolik sistemlerde sicaklık genellikle $60{ }^{\circ} \mathrm{C}$ 'nin altında seyreder [24]. ISO yağ sınıflandırması yapılırken çalışma sıcaklığı olarak $40^{\circ} \mathrm{C}$ esas alınır. Hidrolik yağ ile yürütülen iki saatlik yüke karşı deneylerde elde edilen sıcaklık sonuçlarını şu şekilde açıklamak mümkündür: ISO VG 22 indeksine sahip hidrolik yağın kullanıldığı yük deneyinde elektrik motorunun termal görüntüsü Şekil 8 'de gösterilmiştir. Şekil 8'de görüldüğ̈̈ gibi elektrik motorundaki sıcaklık $55.8{ }^{\circ} \mathrm{C}$ 'ye kadar çıkmıştır. Şekil 8'den anlaşıldığı gibi elektrik motorunun minimum sıcaklık $53.5{ }^{\circ} \mathrm{C}$, maksimum sıcaklık $55.8^{\circ} \mathrm{C}$ olarak ölçülmüştür. Şekil 9'da hidrolik silindirin termal görüntüsü verilmiştir. Burada, hidrolik silindirdeki sıcaklık $44.6{ }^{\circ} \mathrm{C}$ 'ye kadar çıkmıştır. Hidrolik silindirdeki minimum sıcaklık $38.1{ }^{\circ} \mathrm{C}$, maksimum sıcaklık $44.6{ }^{\circ} \mathrm{C}$ olarak ölçülmüştür. Şekil 10 'da hidrolik tankın termal görüntüsüne yer verilmiştir. Tanktaki sıcaklık $43.6{ }^{\circ} \mathrm{C}$ 'ye kadar çıkmıştır. Tanktaki minimum sıcaklık $42.5{ }^{\circ} \mathrm{C}$, maksimum sıcaklık $43.6^{\circ} \mathrm{C}$ olarak ölçülmüştür. Şekil 11 'de hidrolik valfin termal görüntüsü verilmiştir. Buradaki sıcaklık $45.7^{\circ} \mathrm{C}$ 'ye kadar çıkmıştır. Minimum sıcaklık $42.5^{\circ} \mathrm{C}$, maksimum sıcaklık $45.7{ }^{\circ} \mathrm{C}$ olarak ölçülmüştür.
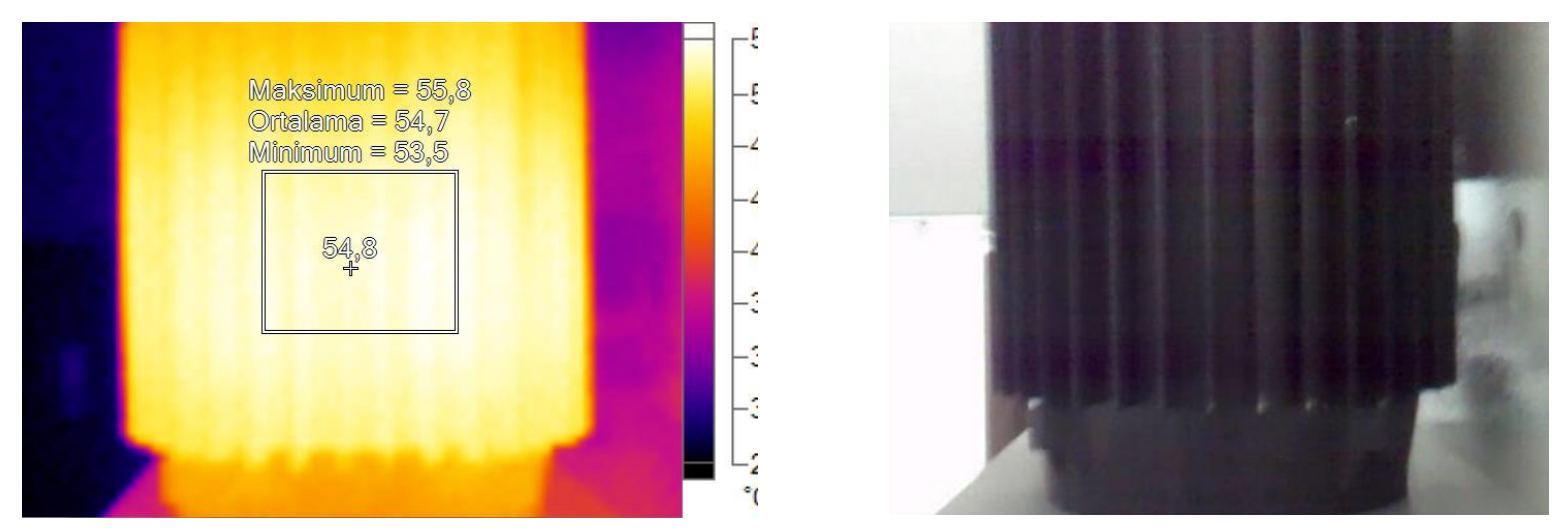

Şekil 8. Yă̆ deneyi için elektrik motorunun termal ve normal görüntüsü 

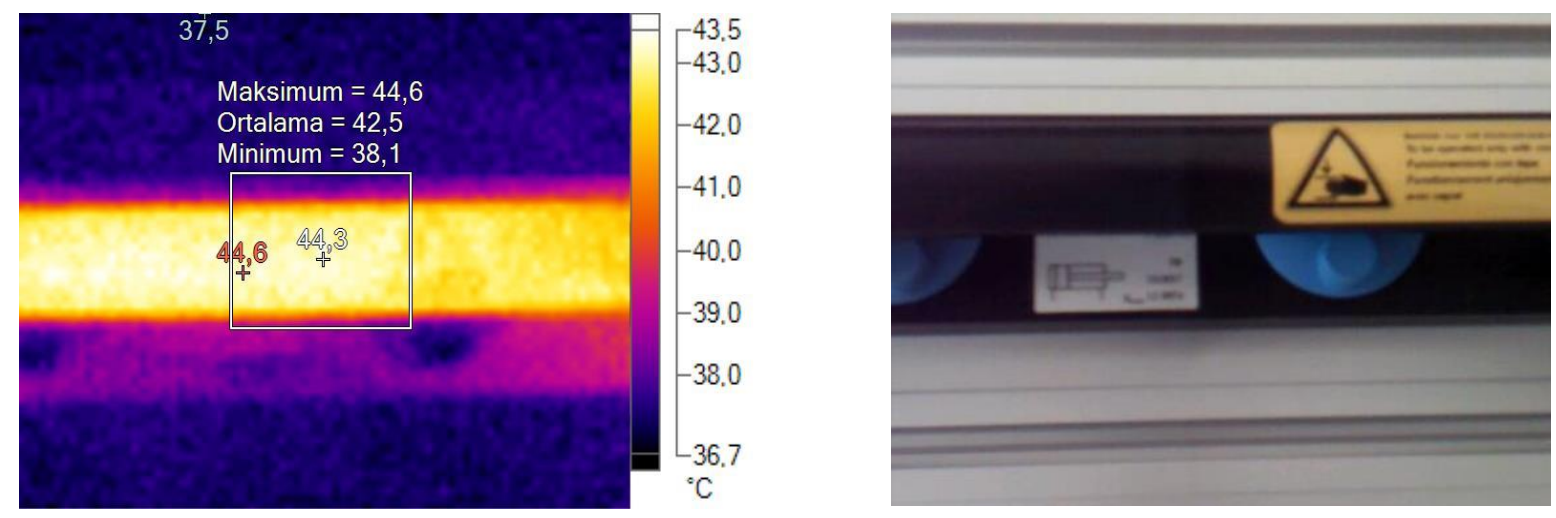

Şekil 9. Yağ deneyi için hidrolik silindirin termal ve normal görüntüsü
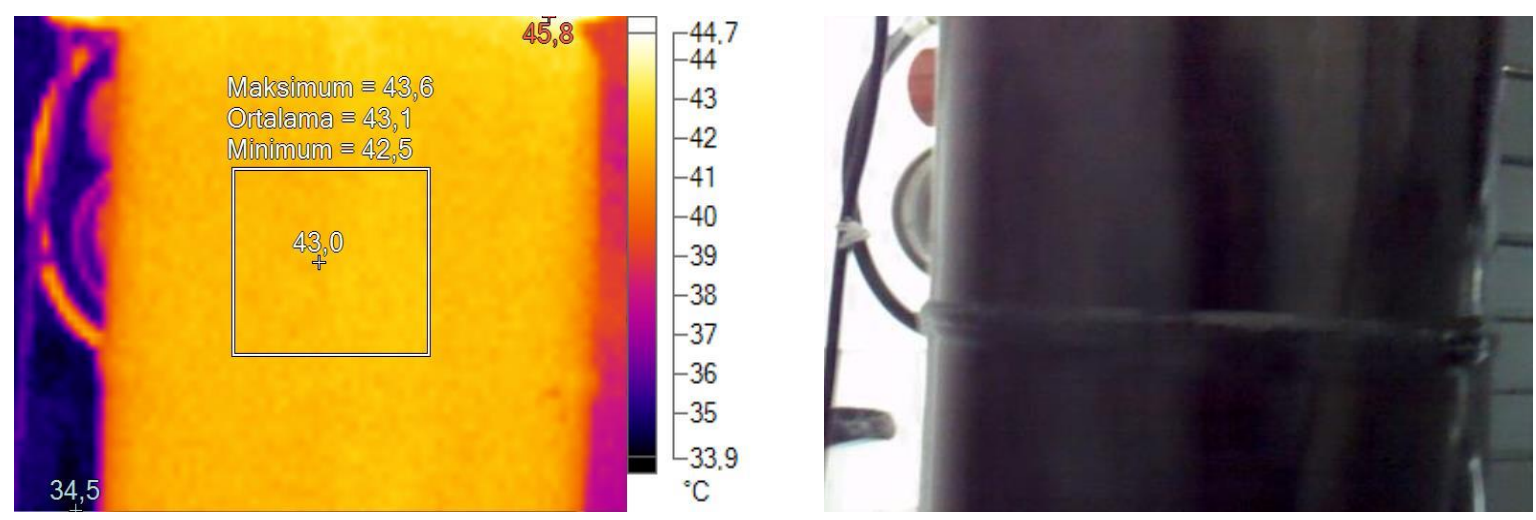

Şekil 10. Yağ deneyi için hidrolik tankın termal ve normal görüntüsü
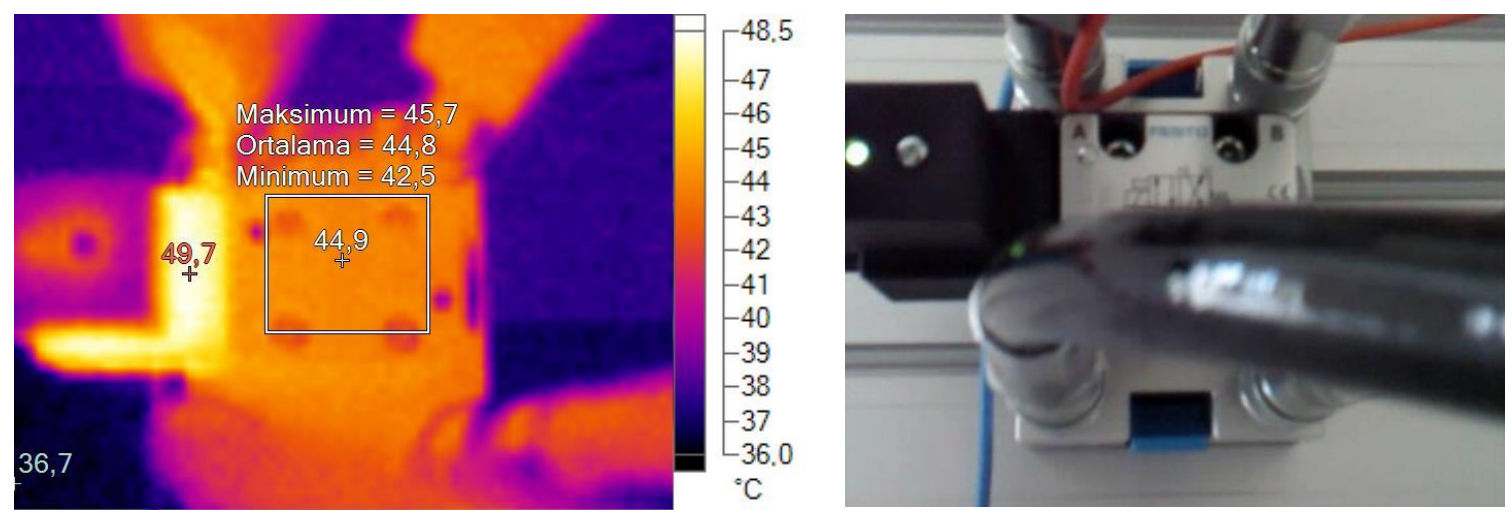

Şekil 11. Yağ deneyi için valfin termal ve normal görüntüsü

\section{SONUC}

$\mathrm{Bu}$ çalışmada bitki karışımları ve ters ozmos yöntemiyle arıtılmış sudan hidrolik akışkan üretilmiş, üretilen bu akışkanın ISO VG 22 sınıfına sahip hidrolik yă̆ ile performansı karşılaştırılmıştır. Karşılaştırmalarda iki farklı yol izlenmiştir. İlk karşılaştırma deneylerinde 10 farklı elektro-hidrolik devre şeması kullanılmıştır. Daha sonra $9 \mathrm{~kg}$ yük kullanılarak yüke karşı akışkanların performansı 
denenmiştir. Yük deneyleri iki saat yapılabilmiş iki saatin sonunda hidrolik pompa arıza vermiştir. Çalışmadan elde edilen sonuçları şu şekilde sıralamak mümkündür.

- Sivı elde etme çalışmalarından 20-100 $\mathrm{mm}^{2} / \mathrm{sn}$ aralığı dikkate alınarak ortalaması 47,6560 mm² /sn viskozite indeksine sahip sıvı deneyler için seçilmiştir.

- Farklı devre şemaları ile yürütülen deneylerde elde edilen hidrolik sıvının kullanıldığı hidrolik devre düzeneğinde kaçaklara rastlanmamıştır.

- Sıvının kullanıldığı hidrolik sistemde kullanılan hidrolik pompanın, normal sisteme göre daha fazla zorlandığı tespit edilmiştir. Bunun nedeni elde edilen sıvının içindeki parçacıkların pompa filtresinden geçerken zorlanması olarak düşünülmektedir. Hidrolik güç ünitesinde 90 mikronluk geri dönüş filtresi yer almaktadır.

- Hız açısından normal hidrolik yağ ile kullanım arasında her hangi bir farklılık gözlemlenmemiştir. Her iki sıvı içinde hidrolik silindirlerin kurslarını tamamlama süresi aynidir.

- Deneyler sonunda üretilen akışkanın kullanıldığı sistemde 4/2 yön kontrol valfi arızalanmıştır. Valf tedarikçi firmaya gönderilmiş ve arızanın sıvı içerisinde meydana gelen tortulardan kaynaklandığı bildirilmiştir.

- İki saatlik çalışma sonunda elektrik motorundan termal kamera ile alınan görüntülerde sıvı kullanılan sistemde en yüksek sıcaklık $55.5^{\circ} \mathrm{C}$, yağ ile yağ kullanılan sistemde en yüksek sıcaklık $55.8^{\circ} \mathrm{C}$ ölçülmüştür. Yağdaki sıcaklık, sıvıya göre \%1.0054 oranında artış göstermiştir.

- Yük deneyinde iki saatin sonunda üretilen sıvının kullanıldığı pompa arıza vermiştir. Sıvının içindeki tortulardan filtrenin tıkandığı düşünülmektedir.

- Hidrolik silindirlerden termal kamera ile alınan görüntülerde sıvı kullanılan sistemde en yüksek sıcaklık $30{ }^{\circ} \mathrm{C}$, yağ kullanılan sistemde en yüksek sıcaklık $44.6{ }^{\circ} \mathrm{C}$ olarak ölçülmüsştür. Yağ kullanılan hidrolik silindirdeki sıcaklık, sıvının kullanıldığı hidrolik silindire göre \%1.486 oranında artmıştır.

- Hidrolik tank için termal kamera ile alınan görüntülerde sıvı kullanan sistemde en yüksek sıcaklık $42.9{ }^{\circ} \mathrm{C}$, yağ kullanılan sistemde en yüksek sıcaklık $43.6{ }^{\circ} \mathrm{C}$ olarak ölçülmüştür. Yağ kullanılan tanktaki sıcaklık, sıvının kullanıldığı tanka göre \%1.0163 oranında artmıştır.

- Hidrolik valf için termal kamera ile alınan görüntülerde sıvı kullanan sistemde en yüksek sicaklık $34.4^{\circ} \mathrm{C}$, yağ kullanılan sistemde en yüksek sıcaklık $45.7^{\circ} \mathrm{C}$ olarak ölçülmüştür. Yağ kullanılan valfteki sıcaklık, sıvının kullanıldığı valfe göre \%1.328 oranında artmıştır.

- Termal kamera görüntüleri sonucunda üretilen akışkanın yağa göre daha az 1sındığı gözlemlenmiştir.

Sonuç olarak üretilen sıvının hidrolik yağa göre tasarlanmış ekipmanlar ile kullanımı uzun vadede uygun olmadığı görülmüştür. Hidrolikte yüksek sıcaklığın olumsuz etkileri düşünüldüğünde üretilen sıvının hidrolik yağa göre sistemi daha düşük sıcaklıkta tuttuğu olumlu bir avantaj olarak söylenebilir. Sıvının 
iyi düzeyde bir filtreleme işleminden geçirilmesi ve su kullanımına uygun hidrolik ekipmanlarla kullanılmasının daha uygun olacağı sonucuna varılmıştır. Ayrıca bu durum, ayrı bir çalışma olarak sunulabilir.

TEŞEKKÜR: Bu çalışma Düzce Üniversitesi Bilimsel Araştırma Projeleri tarafından desteklenmiştir (Proje no: 2016.06.06.439).

\section{$\underline{\text { V. KAYNAKLAR }}$}

[1] R. Doddannavar and A. Barnard, Hydraulic Systems, Operating and Troubleshooting for Engineers \& Techncians, Elsevier Science, 2005.

[2] E. Kassfeldt and G. Dave, "Environmentally adapted hydraulic oils", Wear, vol. 207, pp. 41$45,1997$.

[3] G. H. Lim, P. S. K. Chua and Y. B. He, "Modern water hydraulics-the new energy transmission technology in fluid power", Applied Energy, vol. 76, pp. 239-246, 2003.

[4] E. Urata, "Technological aspects of the new water hydraulics", The Sixth Scandinavian International Conference on Fluid Power (SICFP'99), Tampere, Finland, 1999.

[5] B. Wolfgang, "Water-or oil-hydraulics in the future", The Sixth Scandinavian International Conference on Fluid Power (SICFP’99), Tampere, Finland, 1999.

[6] J. E. G. Van Dam, B. de Klerk-Engels, P.C. Struik and R. Rabbinge, "Securing renew-able resource supplies for changing market demands in a bio-based economy" Industrial Crops and Products, vol. 21, pp. 129-144, 2005.

[7] S. Ergür, "Hidrolik sistemlerde kullanılan bitkisel esaslı hidrolik sıvılar", 6. Ulusal Hidrolik Pnömatik Kongresi, İzmir, 2011.

[8] X. Paredes, M. J. P. Comunas, A. S. Pensado, J. P. Bazile, C. Boned and J. Fernandez, "High pressure viscosity characterization of four vegetable and mineral hydraulic oils", Industrial Crops and Products, vol. 54, pp. 281-290, 2014.

[9] M. Acapoğlu, "Tarım makinalarında biyolojik ayrışabilir yağların hidrolik yağı olarak kullanılması", Ekoloji Çevre Dergisi, c. 20, ss. 9-13, 1996.

[10] E. Durak, E. Çulcuoğlu ve F. Karaosmanoğlu, "Hidrolik yağların katkıları", 2. Ulusal Hidrolik Pnömatik Kongresi ve Sergisi, İzmir, 2001, ss. 37-45.

[11] M. B. Demiralp, "Hidrolik silindirlerde yağ içinde hava problemi", 1. Ulusal Hidrolik Pnömatik Kongresi, Aral1k, İzmir, 1999, ss. 361-363. 
[12] T. Kazuhisa, Y. Tsoyoshi, I. Shigeru and T. Koji, , "Application of simple adaptive control to water hydraulic servo cylinder system", Chinese journal of mechanical engineering, vol. 25, no. 5, pp. 882-888, 2012.

[13] T. E. Christensen and A. P. Bimbo, "Fish oil for use as hydraulic oil", Bioresource Technology, vol. 56, pp. 49-54, 1996.

[14] F. Majdic, J. Pezdirnik and M. Kalin, "Experimental validation of the lifetime performance of a proportional 4/3 hydraulic valve operating in water", Tribology International, vol. 44, pp. 2013-2021, 2012.

[15] M. Kalin, S. Novak and J. Vizintin, "Surface charge as a new concept for boundary lubrication of ceramics with water", Journal of Physics D: Applied Physics, vol. 39, pp. 3138-3149, 2006.

[16] P. Andersson, "Water-lubricated pin-on-disk tests with ceramics", Wear, vol. 154, pp. 37-47, 1992.

[17] M. Kalin, S. Jahanmir and G. Drazic, "Wear mechanisms of glass-infiltrated alumina sliding against alumina in water", Journal of the American Ceramic Society, vol. 88, pp. 346-352, 2005.

[18] S. Li and W. Bao, "Influence of magnetic fluids on the dynamic characteristics of a hydraulic servo-valve torque motor", Mechanical Systems and Signal Processing, vol. 22, pp.1008-1015, 2008.

[19] S. Li and Y. Song, "Dynamic response of a hydraulic servo-valve torque motor with magnetic fluids", Mechatronics, vol. 17, pp. 442-447, 2007.

[20] M. P. Schneider, "Review plant-oil based lubricants and hydraulic fluids", Journal of the Science of Food and Agriculture, vol. 86, pp. 1769-1780, 2006.

[21] K. Kamalakar, A. K. Rajak, R. B. N. Prasad and M. S. L. Karuna, "Rubber seed oil-based biolubricant base stack: A potential source for hydraulic oils", Industral Crops and Products, vol. 51, pp. 249-257, 2013.

[22] D. Merkle,B. Schrader and M. Thomes, Hydraulisc - Basic Level, Festo Didactic, 1998.

[23] D. Merkle, H. Werner, Electrohydraulics-basic level, Festo Didactic, 2003.

[24] A. K. Güven, "Hidrolik yağların ana fonksiyonları ve hidrolik yağ seçimi”, 2. Ulusal Hidrolik Pnömatik Kongresi ve Sergisi, İzmir, 2001, ss. 133-146. 